\title{
A APLICAÇÃo gENERALIZADA dA PRISÃo PREVENTIVA NO CENÁRIO JURÍDICO BRASILEIRO
}

Loana Cristina Proença Silva, Anna Laura dos Santos Constancio

Universidade do Oeste Paulista, Curso de Direito, Presidente Prudente, SP. E-mail: loana proenca@hotmail.com

\section{RESUMO}

O objetivo do projeto é uma breve analise para demonstrar a realidade do sistema prisional brasileiro, pautado em pesquisas junto ao ordenamento jurídico, bem como com a leitura de artigos e doutrinas. É possível observar que com a ocorrência de rebeliões e a explosão da crise penitenciaria no País, busca-se a raiz do problema o qual recai sobre o judiciário. Entretanto, esses fatos relatados não impedem que determinado Juiz decrete a prisão preventiva do agente que tenha cometido crimes que ameaçam a ordem pública. Clara é a necessidade de um choque de administração nos quesitos da Cultura, Educação, Saúde, Economia, Segurança Pública entre outros. As desigualdades sociais devem ser combatidas, a Educação e a Cultura necessitam de uma atenção especial e com urgência, como também o sistema prisional.

Palavras-Chave: Punição Antecipada. Prisão Preventiva Como Medida Cautelar. Processo Penal.

\section{THE GENERALIZED APPLICATION OF PREVENTIVE PRISON IN THE BRAZILIAN LEGAL SCENARIO}

\begin{abstract}
The project is a brief review to demonstrate the reality of the Brazilian system, to take the examination next to the legal system, it is like reading the articles and the tools. It is possible to observe that with an explosion of rebellion and a crisis of penitence in the country, a root of the problem of return on the judiciary is sought. However, these related facts do not prevent the preventive detention of the agent who has committed crimes that threaten public order. Clara is a management shock in the areas of Culture, Education, Health, Economy, Security. Social inequalities must be combated, an education and a culture of special and urgent attention, as well as the prison system
\end{abstract}

Keywords: Early Punishment. Probation as a Precautionary Measure. Criminal Procedure. 


\section{INTRODUÇÃO}

Qualquer pessoa é detentora de direitos e garantias fundamentais, dentre elas, o direito à liberdade, esta compreendida pela autonomia do homem que vive conforme o seu livre arbítrio.

Porém, vivemos em sociedade, sendo assim, apesar de ser livre em tomar decisões, a pessoa deve respeitar os controles impostos pela lei, na intenção de garantir o bom convívio social. Com isso, a liberdade de um indivíduo não deve interferir na liberdade de outro. Caso as limitações sejam ultrapassadas, o agente deve ser responsabilizado e punido.

Nesse campo encontramos o alcance do Direito, como meio regulador de comportamentos, de coibir abusos e responsabilizar os agentes infratores dos preceitos normativos.

Quando no convívio social, após a prática delitiva, emerge o risco da manutenção da pessoa em liberdade, seja porque há o risco de fuga, seja porque possa o indivíduo reiterar na prática delituosa contra o mesmo bem jurídico ou bens jurídicos análogos, ou ainda, ocultar, desfigurar, destruir ou, por qualquer meio, embaraçar a produção probatória, o Direito Processual Penal se vê na necessidade de reprimir tais condutas, garantindo o resultado satisfatório do processo, assegurando a tranquilidade social e privilegiando a credibilidade da Justiça Criminal e até mesmo da crença na lei penal.

O Direito Processual Penal, como ramo do direito, também tem o seu objetivo primordial, que é caminho necessário para se alcançar a pena estando condicionado ao exercício do poder de penar exercido pelo Estado.

Com caráter instrumental o Processo Penal evoluiu a aplicação da pena com uma importantíssima relação entre o delito, pena e processo, relação essa que caracterizou a superação da vingança privada e estabeleceu os primordiais critérios da justiça.

Norberto Avena $(2005$, p.8) remete ao conceito que afirma:

A realização de uma conduta típica faz nascer, para o Estado, o poder-dever de aplicar a sanção penal correspondente. Essa aplicação, contudo, não poderá ocorrer à revelia dos direitos e garantias fundamentais do indivíduo, sendo necessária a existência de um instrumento que, voltado à busca da verdade real, possibilite ao imputado contrapor-se à pretensão estatal.

Com isso, Aury Lopes Jr (2017, p. 33) evidencia que o processo não pode ser considerado como mero instrumento:

\footnotetext{
Por fim, o processo não pode mais ser visto como um simples instrumento a serviço do poder punitivo (Direito Penal), se não que desempenha o papel de limitador do poder e garantidor do indivíduo a ele submetido. Há que se compreender que o respeito às garantias fundamentais não se confunde com impunidade, e jamais se defendeu isso. 0 processo penal é um caminho necessário para chegar-se, legitimamente, à pena. Daí por que somente se admite sua existência quando ao longo desse caminho forem rigorosamente observadas as regras e garantias constitucionalmente asseguradas (as regras do devido processo legal).
}

\section{OBJETIVO}

O objetivo do artigo é analisar a generalização da prisão preventiva, uma vez que o EstadoJuiz tem aplicado tal medida com desacerto, desvirtuando o caráter assecuratório da mesma. Ademais tal atitude vai de encontro com as garantias constitucionais que asseguram a todo cidadão o direito à liberdade, e por consequência abarrotando o sistema prisional brasileiro. 


\section{METODOLOGIA}

O presente artigo utilizou-se de pesquisas junto as normas presente no ordenamento jurídico brasileiro e doutrinadores consideráveis na matéria estudada. Utilizando o método que buscou uma discussão partindo do raciocínio lógico geral para o particular, com intuito de cumprir o objetivo proposto.

\section{GENERALIZAÇÃO DA PRISÃO PREVENTIVA: NOÇÕES GERAIS}

Lamentavelmente as prisões cautelares estão sendo inseridas como forma de urgência, desempenhando então um relevantíssimo efeito sedente da opinião pública pela ilusão da justiça instantânea.

Conclui então Aury Lopes Jr (2014, p. 583):

O simbólico da prisão imediata acaba sendo utilizado para construir uma (falsa) noção de "eficiência" do aparelho repressor estatal e da própria justiça. Com isso, o que foi concebido para ser "excepcional" torna-se um instrumento de uso comum e ordinário, desnaturando-o completamente. Nessa teratológica alquimia, sepulta-se a legitimidade das prisões cautelares. Conclui-se, portanto, que o problema não é legislativo, mas cultural.

O presente artigo traz uma nova visão de resolução na concepção de como podemos entender o nosso conjunto legal. E para isso o juiz exerce relevante função que é de materializar os princípios constitucionais para a vida real, agindo como um guardião dos direitos e garantias fundamentais.

Na lição de CARNELUTTI (1950, p.75):

As exigências do processo penal são de tal natureza que induzem a colocar o imputado em uma situação absolutamente análoga ao de condenado. É necessário algo mais para advertir que a prisão do imputado, junto com sua submissão, tem, sem embargo, um elevado custo? O custo se paga, desgraçadamente em moeda justiça, quando o imputado, em lugar de culpado, inocente, e já sofreu, como inocente, uma medida análoga à pena; não se esqueça de que, se a prisão ajuda a impedir que o imputado realize manobras desonestas para criar falsas provas ou para destruir provas verdadeiras, mais de uma vez prejudica a justiça, porque, ao contrário, Ihe impossibilita de buscar e de proporcionar provas úteis para que o juiz conheça a verdade. A prisão preventiva do imputado se assemelha a um daqueles remédios heroicos que devem ser ministrados pelo médico com suma prudência, porque podem curar o enfermo, mas também pode ocasionar-lhe um mal mais grave; quiçá uma comparação eficaz se possa fazer com a anestesia, e sobretudo com a anestesia geral, a qual é um meio indispensável para o cirurgião, mas ah se este abusa dela!

Nessa trajetória, estamos perante o magistrado que tem sobre si a responsabilidade de decisões que determinam o destino do agente, principalmente do mais carente, submetido em quase todos os aspectos ao Estado, mas de modo infeliz continua "desfalcado", pois nunca recebe o que necessita e tem direito, sendo assim sua condenação criminal passa a ser mais uma violência enfrentada, seja por ação ou omissão, em sua infeliz trajetória.

Mas devemos levar em extrema consideração a propositura da prisão preventiva, mas a propositura de fato necessária ao caso, sendo assim a prisão preventiva é necessidade para o país, porém se não aplicada da forma devida ao agente e se torna um problema imensurável.

A condição para se decretar uma medida coercitiva não é a possibilidade da presença do direito de acusação, mas sim de um fato a ser punido. Sendo assim, é correto dizer que a premissa para decretação da prisão preventiva é a existência da aparência do fato delituoso, enquanto veracidade de um delito.

No processo penal, o fator determinante para a aplicação da prisão cautelar, não seria o 
tempo, mas a circunstância perigosa criada pela atuação do imputado. Entende-se como um risco da frustação punitiva, isto é, a fuga do agente ou causar graves prejuízos ao processo na possibilidade da ausência do acusado.

De acordo com a interpretação de Aury (2014, p. 574):

O risco no processo penal decorre da situação de liberdade do sujeito passivo. Basta afastar a conceituação puramente civilista para ver que o periculum in mora no processo penal assume o caráter de perigo ao normal desenvolvimento do processo (perigo de fuga, destruição da prova) em virtude do estado de liberdade do sujeito passivo.

Logo, o fundamento é um periculum libertatis, enquanto perigo que decorre do estado de liberdade do imputado.

Efetuada então tais considerações, avancemos para a fundamentação da prisão preventiva: Art. 312. A prisão preventiva poderá ser decretada para a garantia da ordem pública, da ordem econômica, por conveniência da instrução criminal, ou para assegurar a aplicação da lei penal, quando houver prova da existência do crime e indício suficiente de autoria.

Parágrafo único. A prisão preventiva também poderá ser decretada em caso de descumprimento de qualquer das obrigações impostas por força de outras medidas cautelares (art. 282, § $4 \circ$ ㅇ, CPP).

O que podemos observar do referido acima é que toda restrição a direitos individuais, junta com a exigência de ordem pública e fundamentação do juiz, tem em conta a necessidade e a adequação da medida.

Então a regra deve ser de preferência a imposição das cautelares diversas a prisão, deixando a preventiva para casos de maios gravidade, onde as circunstâncias tragam grande ameaça a eficácia da lide ou reiteração criminosa.

Entende-se então que a necessidade e adequação são de fundamental importância para a aplicação da medida, e ambas se reúnem para a formação do princípio da proporcionalidade

Seguimos com a ilustríssima ideia de Eugênio (2017, p. 512)

O postulado da proporcionalidade, presente implicitamente em nossa Constituição, por dedução do conjunto geral das garantias individuais, exerce uma dupla função no Direito, a saber:

a) na primeira, desdobrando-se, sobretudo, na proibição do excesso, mas, também, na máxima efetividade dos direitos fundamentais, serve de efetivo controle da validade e do alcance das normas, autorizando o intérprete a recusar a aplicação daquela (norma) que contiver sanções ou proibições excessivas e desbordantes da necessidade de regulação;

b) na segunda, presta-se a permitir um juízo de ponderação na escolha da norma mais adequada em caso de eventual tensão entre elas, ou seja, quando mais de uma norma constitucional, se apresentar como aplicável a um mesmo fato.

Como regra, nenhuma providência cautelar pode ser superior ao resultado final do processo a que se destina tutelar.

Eugênio (2017, p. 514), continua na sistemática:

Há também manifesta proporcionalidade em relação aos crimes culposos, para os quais permanece vedada a prisão preventiva, ressalvada a hipótese do art. 313, parágrafo único, CPP, limitada a prisão para e até a identificação do acusado. Ora, se o art. 44, I, CP, autoriza a substituição da pena, qualquer que seja aquela aplicada, para os crimes culposos, por que razão se recorrer à prisão preventiva??? Aqui, a desproporção da medida restaria evidente! A medida cautelar seria mais grave que a pena aplicada! 


\section{CONCLUSÃO}

Isto posto, infelizmente, a prisão preventiva é uma necessidade em nosso País. Por óbvio, os Magistrados devem analisar o caso concreto para que os Direitos Constitucionais de cada indivíduo sejam respeitados.

Em toda história do mundo moderno, nunca tivemos resultados positivos no encarceramento como forma de combate ao crime e política de segurança pública. Todos os países que diminuíram as taxas de violência foram com investimento em educação e igualdade social, de forma que após anos de políticas voltadas para esse fim maior, começaram a desativar suas prisões, pois não são mais necessárias.

Violência e Criminalidade se combatem com igualdade social. Entretanto, faz-se necessário o investimento com foco na educação, lazer e reais oportunidades aos menos favorecidos. Como já dizia Ruy Barbosa, o ideal "é tratar igualmente os iguais e desigualmente os desiguais, na medida de suas desigualdades", mas existe um hiato para a efetividade desse princípio ímpar, o qual necessita de atitudes supramencionadas que possibilitarão maior aproximação a esse ideal da igualdade.

\section{REFERÊNCIA}

ASSUNÇÃO, Rafael Francatto. Prisão preventiva: Problema ou necessidade? JusBrasil, ago. 2016. Disponível em: <https://francatto9.jusbrasilcom.br/artigos/423328553/prisão-preventivaproblema-08-necessidade>. Acesso: 17 ago.2018;

AVENA, Norberto. Manual de Processo Penal 3. ed. rev., atual. e ampl. - Rio de Janeiro: Forense; São Paulo: Método: 2015.

BOTTURA, Vitor Raatz. Generalização das prisões cautelares pode representar grave erro, Revista Consultor Jurídico, 25 de jun. de 2014. Disponível em: <https://www.conjur.com.br/2014-jun25/generalizacao-prisoes-cautelares-representar-grave-erro>. Acesso em:16 ago. 2018.

BOTTURA, Vitor Raatz. O problema da generalização das prisões cautelares. Revista Jus Navigandi, ISSN 1518-4862, Teresina, ano 20, n. 4461, 18 set. 2015. Disponível em: <https://jus.com.br/artigos/33572>. Acesso em: 17 ago. 2018.

BRASIL. Decreto-Lei n.o 3.689, de 3 de outubro de 1941. Código de Processo Penal. Diário Oficial da União, Brasília, DF, 3 out.1941. Disponível em: http://www.planalto.gov.br/ccivil 03/decretolei/Del3689.htm. Acesso em 19 de mar. 2018.

CARNELUTTI, Francesco. Lecciones sobre el Processo Penal. Trad. Santiago Santís Melendo. v. II Buenos Aires, Bosch, 1950.

LOPES JUNIOR, Aury. Direito processual penal. 11. ed. - São Paulo: Saraiva, 2014.

LOPES JUNIOR, Aury. Direito processual penal. 14. ed. - São Paulo: Saraiva, 2017.

PACELLI, Eugênio. Curso de processo penal. 21. ed. rev., atual. e ampl. - São Paulo: Atlas, 2017.

RODRIGUES, Isabelle Cristina. Princípio da igualdade e a discriminação positiva, Conteúdo Jurídico, Ourinhos - SP 31 de jul. de 2012. Disponível em: <http://www.conteudojuridico.com.br/artigo,principio-da-igualdade-e-a-discriminacao- 
positiva,38099.html >. Acesso em: 16 ago. 2018. 